\title{
GEOGRAFIA CAMPONESA E O ENCONTRO COM A EDUCAÇÃO DO CAMPO
}

\author{
Peasant geography and meeting with Rural Education
}

Bernadete Maria Coêlho Freitas ${ }^{1}$

\begin{abstract}
RESUMO: Este artigo tem como premissa analisar os camponeses como categoria de análise, a partir de aportes filosóficos e teóricos da Geografia Humana, especialmente, dos estudos agrários, com vínculo inexorável à questão agrária, apreendendo elementos de aproximação com a Educação do Campo. Desse ponto de partida, decorre a discussão sobre camponeses como classe social, insurgindo do capitalismo, com sustentação nas obras de Teodor Shanin, Ariovaldo Umbelino de Oliveira, José de Souza Martins, dentre outros. Ontologicamente, retoma à ideia de totalidade e o condicionamento histórico-social dessa classe, consubstanciada pelas contradições, tensões e lutas em defesa de direitos. O encontro entre a geografia camponesa e a Educação do Campo projetase, principalmente, na construção do território, materializada na luta pela permanência dos/as camponeses/as na terra, considerando seu modo de vida, isto é, pela territorialização e territorialidade camponesas, condição essencial para reprodução social e (i)material da vida.
\end{abstract}

Palavras-chave: Geografia Humana. Questão Agrária. Camponeses. Educação do Campo.

\begin{abstract}
This article aims to analyze the peasants as a category of analysis based on philosophical and theoretical contributions of Human Geography, especially from agrarian studies, with an inexorable connection to the agrarian question, understanding elements of approximation with Rural Education. From this starting point arises the discussion about peasants as a social class, rising from capitalism, supported by the works of Teodor Shanin, Ariovaldo Umbelino de Oliveira, José de Souza Martins, among others. Ontologically, it returns to the idea of totality and the historical-social conditioning of this class, consolidated by contradictions, tensions, and struggles in defense of rights. The encounter between peasant geography and Rural Education is projected, mainly, in the construction of the territory, materialized in the struggle for the permanence of the peasants on the land, considering their way of life, that is, for the territorialization and peasant territoriality, an essential condition for social and (i) material reproduction of life.
\end{abstract}

Keywords: Human Geography. Agrarian Question. Peasants. Rural Education.

\section{CONSIDERAÇÕES INICIAIS}

Os estudos dos camponeses têm sido construídos, direta ou indiretamente, tanto por autores do ramo da Geografia, como de outras áreas do conhecimento, como Sociologia, Economia, História, Filosofia etc., em diferentes escalas espaço-temporais, seja reafirmando sua recriação e reprodução social, seja defendendo sua extinção. Essas construções teóricas alimentam

\footnotetext{
${ }^{1}$ Doutora em Geografia Humana pela Universidade de São Paulo (USP). Professora Adjunta do Curso de Licenciatura em Educação do Campo - Ciências Humanas e Sociais, da Universidade Federal do Piauí (UFPI), Campus Professora Cinobelina Elvas (CPCE), em Bom Jesus (PI). E-mail: $\underline{\text { berna@,ufpi.edu.br }}$
} 
e, dialeticamente, são alimentadas pela visão social de mundo dos estudiosos, acarretando implicações na reprodução da vida camponesa, que permanece lutando para comprovar sua existência e garantir direitos, dentre os quais, a terra, o território e a educação do campo.

O sociólogo russo Teodor Shanin ${ }^{2}$ pode ser considerado uma das principais referências do pensamento crítico sobre o campesinato. Esse autor analisou a obra de Karl Marx, apresentando alguns escritos pouco disseminados, fundamentando sua leitura marxiana contra o marxismo doutrinário, em defesa de uma visão mais aberta da realidade, a partir do condicionamento histórico e dialético, criticando, juntamente com Marx, os marxistas que se negavam a aceitá-la, como é o caso de G. Plekhanov e Karl Kautsky, ao desconsiderarem a existência histórica dos camponeses, como expressão do movimento contraditório e combinado do capitalismo.

Shanin foi também, o principal estudioso da obra de Alexander Chayanov, porém, manteve sua autonomia de criação na teoria que construiu sobre os camponeses, contribuindo para os estudos desse tema em diferentes regiões do mundo. Sua abordagem perpassa pelo entendimento dos camponeses como classe, revela a economia política do campesinato, estabelece uma leitura geral e específica desses sujeitos, bem como, sobre suas características centrais, problemáticas e organicidade política. Na Geografia Humana, especialmente nos estudos agrários, esse autor colaborou para uma leitura abrangente, crítica e totalizante dos camponeses no contexto da questão agrária, influenciando autores brasileiros, como Ariovaldo Umbelino de Oliveira, referência dessa área de conhecimento no país.

Este trabalho encontra sustentação nas obras desses autores, dentre outros, considerando os camponeses como uma classe social insurgindo do capitalismo, que recria e reproduz relações não especificamente capitalistas de produção como uma das condições para a reprodução ampliada do capital (OLIVEIRA, 1999; MARTINS, 1981). Partindo dessa premissa, entende-se que os camponeses não constituem-se grupos sociais em extinção, mas uma classe que tem lutado historicamente para manter-se na terra, assegurando sua reprodução social e (i)material de vida, isto é, sua territorialização e territorialidade, embora subordinados ao capital pela sujeição da renda da terra, conforme mostrou Martins (1981), e através da monopolização do território pelo capital, no dizer de Oliveira (1999).

$\mathrm{Na}$ Geografia, o debate sobre a construção do território ${ }^{3}$ e, consequentemente, a territorialização e a territorialidade camponesas aproximam o diálogo com a Educação do Campo,

\footnotetext{
2 Theodor Shanin faleceu em 2020, deixando um legado não somente pela contribuição ao pensamento camponês, mas por ter apresentado ao mundo um Marx pouco disseminado por alguns de seus seguidores, questões presentes em parte de seus escritos como a obra "Marx tardio e a via russa - Marx e as periferias do capitalismo", no ano de 2017.

${ }^{3}$ O território é o espaço concreto da luta de classes travada pela sociedade na produção material de sua existência, compreendido de forma multidimensional e marcado por relações de poder (OLIVEIRA, 1999; RAFFESTIN, 1993).
} 
política pública voltada aos interesses dos sujeitos, atendendo suas necessidades e especificidades, contradições e tensões sociais (MOLINA; HAGE, 2016). Batista; Molina (2015), nesse sentido, reafirmam que a Educação do Campo, além de lutar por política pública, busca uma educação que considere os contextos locais, a cultura e os desafios enfrentados nos diferentes territórios do campo.

Para essa reflexão, algumas questões são essenciais: no âmbito da questão agrária, quais princípios filosóficos e teórico-metodológicos sustentam a tese da recriação do campesinato, isto é, sua condição de permanência como classe social de dentro do capitalismo? Quais as características centrais dos camponeses, suas origens e o que motiva, no Brasil, o uso da denominação de camponeses, ao invés de agricultores familiares? Partindo desse debate, a ideia é apreender alguns elementos de aproximação entre a Geografia Humana, especialmente a Geografia Agrária com a Educação do Campo. A intenção de problematizar tais questões, a partir de uma análise geográfica interdisciplinar é o que motiva este estudo, sempre aberto ao diálogo e à provocação.

\section{QUESTÃO AGRÁRIA E OS PRINCÍPIOS ONTOLÓGICOS DAS ESCOLHAS TEÓRICO-METODOLÓGICAS}

A questão agrária pode ser compreendida como um conjunto de problemas relacionados ao desenvolvimento do modo capitalista de produção no campo. As transformações territoriais do espaço rural refletem esse entendimento, embora não seja suficiente apenas apresentar essas mudanças, ou seja, as relações entre o capital e os problemas gerados, mas tentar desvelar o que se mostra e, ao mesmo tempo, se esconde no fenômeno (KOSIK, 1976), isto é, evidenciar o movimento do real amparado pela análise da totalidade.

De acordo com Martins (1981), é improvável que alguém discuta os acontecimentos do espaço rural sem atribuí-los à expansão do capitalismo no campo. De certo modo, o capitalismo explicaria até mesmo, as questões que são opostas entre si, como a permanência e a expropriação do campesinato. No entanto, Martins (1981, p. 152) alerta:

Quando dizemos que as grandes transformações que ocorrem no mundo rural são devidas à expansão do capitalismo, não estamos mentindo ou falseando a verdade. Entretanto, estaremos simplificando demais a questão se nos limitarmos a ver meras relações de causa e efeito entre o capital e os problemas que vão surgindo. 
Partindo dessa prerrogativa, a intepretação do campo requer, em primeiro lugar, um retorno ao método filosófico. Desse ponto de vista, a abordagem sobre os camponeses, vinculada de forma inexorável à questão agrária, adota como ponto de partida a ideia de visão social de mundo (LOWY, 2007) específica, dando base às escolhas teórico-metodológicas subsequentes.

Para Lowy (2007), as visões sociais de mundo são manifestadas pelos princípios de utopia, contrapondo-se ao de ideologia, tendo esse primeiro, um potencial subversivo e revolucionário contra a ordem social desigual, diferente da visão estreita de "sonho irrealizável" e, esse último, vinculado à ideia de manutenção da estrutura societal desigual, daí o caráter conservador das ideologias, visão que vai além da perspectiva de falseamento da realidade apresentada por Marx. Cumpre salientar que a utopia pode apresentar num certo momento da história esse caráter utópico revolucionário, tornando-se posteriormente, uma ideologia de base conservadora, a exemplo das concepções filosóficas do positivismo, historicismo e de algumas abordagens marxistas.

Nesse sentido, o autor lembra que o positivismo foi criado no fim do século XVIII e início do século XIX, como uma utopia revolucionária em relação à burguesia absolutista, tornando-se, ainda no século XIX, uma ideologia conservadora, perdurando até os dias atuais, dada a identificação com a ordem industrial e burguesa estabelecida. De forma sistemática, os fundamentos de suas principais premissas apontam para esse entendimento, como mostra o autor:

\begin{abstract}
A sociedade é regida por leis naturais, isto é, leis invariáveis, independentes da vontade e da ação humanas; na vida social, reina uma harmonia natural; 2. A sociedade, pode, portanto, ser epistemologicamente assimilada pela natureza [...] estudada pelos mesmos métodos [...] e processos empregados pelas ciências da natureza; 3. As ciências da sociedade, assim como as da natureza, devem limitarse à observação e à explicação causal dos fenômenos, de forma objetiva, neutra, livre de julgamentos de valor ou ideologias, descartando todas as prenoções e preconceitos. (LOWY, 2007, p. 17)
\end{abstract}

Tomando como referência essa reflexão, é perceptível o interesse do positivismo em naturalizar os fenômenos sociais e invisibilizar o protagonismo dos sujeitos sociais na produção material de vida, assim como sua negação ao condicionamento histórico-social e a inexistência relação com as classes sociais. Essas últimas, forjadas em tensões da sociedade e pelas contradições nelas inerentes, conformadas pelos interesses divergentes, seja no sentido de manter ou de desconstruir a ordem estruturante socialmente desigual.

A crítica de Lowy (2007) é estendida ao historicismo, ainda que por razões diferentes. Embora considere suas relevantes contribuições à produção do conhecimento, o fracasso metodológico do historicismo, tanto o conservador como o relativista, é verificado, simultaneamente, pela potência crítica dessa corrente e de sua incapacidade de responder aos 
problemas que ela própria suscita, tornando-se potencialmente inovadora, entretanto, sem conseguir estabelecer caminhos consistentes, diante de tamanha complexidade anunciada.

Em relação ao método dialético (LEFEBVRE, 1975) de cunho marxista, Lowy (2007) destaca a importância da análise sócio-histórica dos escritos de Marx, preconizada como forma de compreender a evolução da ciência social, do ponto de vista científico. Uma contribuição significativa é a de que as lutas de classes não podem ser compreendidas, senão em relação com a história social e econômica, em sua concretude. Alguns teóricos marxistas, por sua vez, caíram no que Lowy (2007, p. 99) chamou de "princípio da carruagem" (tomando o termo anunciado por Max Weber), ante a influência do positivismo, pela extrema dificuldade em aplicar o materialismo histórico a si mesmos. A corrente bistoricista do marxismo, segundo o autor, foi a que apresentou ideias mais profundas acerca da resolução dialética, fugindo das armadilhas do "princípio da carruagem". E o marxismo racionalista tratou de negar a ordem estabelecida e de fomentar o antipositivismo, opondo-se à neutralidade da ciência e defendendo o engajamento como forma de escapar ao relativismo.

Marx, no Livro I, Volume I de O Capital, ao demonstrar as interpretações de seu método, que, segundo ele, não foi bem compreendido, defende o fundamento materialista da dialética, mostrando a necessidade da distinção formal do método de exposição e do método de pesquisa. Retrata uma postura contrária à dialética hegeliana, embora reconheça que Hegel tenha sido o primeiro a apresentar, de forma ampla e consciente, suas formas gerais de movimento:

\begin{abstract}
A investigação tem de apoderar-se da matéria, em seus pormenores, de analisar suas diferentes formas de desenvolvimento e de perquirir a conexão íntima que há entre elas. Só depois de concluído esse trabalho é que se pode descrever, adequadamente, o movimento real. Se isto se consegue, ficará espelhada, no plano ideal, a vida da realidade pesquisada, o que pode dar a impressão de uma construção a priori. [...] Meu método dialético, por seu fundamento, difere do método hegeliano, sendo a ele inteiramente oposto. Para Hegel, o processo do pensamento do real, e o real é apenas sua manifestação externa. Para mim, ao contrário, o ideal não é mais do que o material transposto para a cabeça do ser humano e por ela interpretado. (MARX, 2012, p. 28)
\end{abstract}

Marx critica a dialética hegeliana, ainda pelo caráter de mistificação que apresenta, sendo bastante disseminada na Alemanha à época, de modo que parecia enaltecer a ordem estabelecida, pela concepção anunciada. No seu formato racional, contudo, pelo seu caráter revolucionário, tornava-se perturbador a essa ordem existente, constituindo-se uma ameaça à burguesia, daí seu caráter ideológico de visão social de mundo. Nas palavras de Marx (2012, p. 29):

[...] A dialética mistificada tornou-se uma moda na Alemanha, porque parecia sublimar a situação existente. Mas, na sua forma racional, causa escândalo e 
horror à burguesia e aos porta-vozes de sua doutrina, porque sua concepção do existente, afirmando-o, encerra, ao mesmo tempo, o reconhecimento da negação e da necessária destruição dele; porque apreende, de acordo com seu caráter transitório, as formas em que se configura o devir; porque, enfim, por nada se deixa impor; e é, na sua essência, crítica e revolucionária.

Nesse sentido, a tese da recriação do campesinato no contexto da questão agrária brasileira foi formulada por autores marxistas, que partiram de bases filosóficas críticas ao positivismo e ao historicismo relativista, além da tentativa de fugir das armadilhas do "princípio da carruagem", ao considerarem o condicionamento histórico-social. Essa concepção reafirma a ideia de que o campesinato não irá desaparecer, mas recriar-se e reproduzir-se como classe social, a partir das contradições do próprio capitalismo, conforme defendem Oliveira (1981; 1991; 1999; 2007; 2016), Martins (1979; 1980; 1981), Shanin (1976; 1983; 2008), dentre outros.

Essa abordagem critica também autores marxistas que formularam proposições negando o lugar histórico dos camponeses, isto é, reafirmando seu inexorável desaparecimento, o que impossibilitaria o acesso desses sujeitos às políticas públicas, a exemplo da Educação do Campo. Para Oliveira (1999), esses autores assumem essa visão social de mundo, por desconsiderar a lógica contraditória da reprodução ampliada do capital em relações não especificamente capitalistas de produção.

Segundo Oliveira (1999), os autores marxistas esqueceram o que o próprio Marx afirmou ao defender a existência de três classes sociais, incluindo os proprietários de terras (formada por camponeses e latifundiários, com interesses divergentes), além dos proletários e da burguesia. Além dessa concepção teórica, os argumentos desse autor encontram sustentação do ponto de vista empírico, ao analisar a realidade mundial, desde sua perspectiva histórica, cuja concretude é perceptível na transição do feudalismo para o capitalismo, quando, no berço desse modo de produção, presenciou-se a reprodução camponesa, processo que tem ampliado como mostra Teodor Shanin, em entrevista realizada por Alves; Lima (2018). A questão a ser refletida a esse respeito é sobre as motivações das escolhas teórico-metodológicas desses autores e quais as implicações para os camponeses e os estudos agrários.

O campesinato tem assegurado seu lugar histórico como classe social, alimentando as utopias revolucionárias, questões verificadas no estudo de Wolf (1984), ao discutir as revoluções mexicana, russa, chinesa, vietnamita, argeliana e cubana. No Brasil, vale destacar o papel das Ligas Camponesas, Guerra de Canudos, Contestados, Trombas e Formoso etc. (MARTINS, 1981). Atualmente, pode-se fazer menção ao Movimento dos Trabalhadores Sem Terra (MST), embora não assuma em sua denominação o termo "camponês" e sim "trabalhadores", quiçá pela influência de estudos leninistas em alguns setores, considerando que o movimento é bastante diverso. 
A obra de Lenin sobre o desenvolvimento do capitalismo da Rússia é um exemplo clássico da negação à recriação dos camponeses. Seu estudo teve como objetivo debater a formação do mercado interno para o capitalismo, constando a defesa da tese da diferenciação e da desintegração camponesa. Apresenta dados sobre a economia camponesa da Rússia meridional que, embora se referindo a uma parcela do país, considera "inquestionável a conclusão de que o campesinato está em total desintegração, com o pleno domínio da burguesia camponesa" (LENIN, 1982, p. 46), fruto do processo de diferenciação, no âmbito da expansão do capitalismo. Vale ressaltar a originalidade da obra de Lenin, assim como a de Marx, como bem lembrou Teodor Shanin (ALVES; LIMA, 2018), deixando um legado incontestável.

A obra “A questão agrária” de Karl Kautsky - a quem Lenin (1982, p. 06) atribui “o acontecimento mais notável na literatura econômica moderna”, após O Capital de Marx - sobre o desenvolvimento da agricultura na sociedade capitalista, tornou-se um dos principais estudos a serem disseminadas pelos autores que defendem a tese da destruição do campesinato, ainda que apresente abordagens diferenciadas, referindo-se, inclusive, da continuidade de sua obra por parte de seus seguidores.

E, nesse contexto, ocorreu o afastamento entre Marx e os marxistas, ao passo que alguns deles retornam ao seu pensamento apenas em relação a determinados elementos, como foi o caso de Karl Kautsky. Diversos autores brasileiros, apesar das especificidades de suas abordagens, foram influenciados pela obra de Kautsky, dentre outras, passando a defender a teoria da destruição do campesinato. Autores como Ricardo Abramovay (2007), por exemplo, afirma que no paradigma marxista "o camponês só pode ser definido pela tragédia do seu destino social: será fatalmente extinto pela própria dinâmica da diferenciação entre os produtores (Lênin), bem como será incapaz de resistir à concorrência das grandes empresas agrícolas (Kautsky)” (ABRAMOVAY, 2007, p. 33).

A obra de Rosa Luxemburgo, entretanto, especialmente "A acumulação do capital" - que tenta mostrar o problema da reprodução do capital e, ao mesmo tempo, oferecer subsídio na luta prática contra o imperialismo, à época - tornou-se fundamental para contestar a teoria da destruição do campesinato. Luxemburgo (1988) evidencia, dentre outros elementos, que a acumulação do capital ocorre por duas vias distintas, uma delas na produção de mais-valia, culminando na relação entre capitalistas e assalariados e, outra, entre o capital e as formas de produção não-capitalistas, sob parâmetros imperialistas no contexto mundial, como esclarece:

A acumulação de capital como um todo, como processo histórico concreto, apresenta, pois, dois aspectos distintos. Um deles desenvolve-se nos centros produtores da mais-valia - nas fábricas, nas minas, nas propriedades agrícolas e no mercado. Visto sob esse ângulo, a acumulação é um processo puramente econômico - cuja fase mais importante se realiza entre os capitalistas e os 
trabalhadores assalariados e cujas duas fases (no espaço fabril e no mercado) desenvolvem-se exclusivamente dentro dos limites estabelecidos pela troca de mercadorias e pela troca de equivalentes [...] O outro aspecto da acumulação de capital é o que se verifica entre o capital e as formas de produção não-capitalistas. Seu palco é o cenário mundial. Como métodos da política colonial reinam o sistema de empréstimos internacionais, a política das esferas de influência e as guerras [...] Na realidade, a violência política é apenas o veículo do processo econômico; ambos os aspectos da reprodução do capital encontram-se interligados organicamente, resultando dessa união a trajetória histórica do capital. (LUXEMBURGO, 1988, p. 86-87)

Sua leitura central é a de que o desenvolvimento do capitalismo ocorre não apenas por meio da reprodução ampliada de capital, através da fórmula D-M-D’ (em que D é dinheiro, M é mercadoria e D’ é mais dinheiro), mas também, pela via da produção de capital, isto é, M-D-M (em que $\mathrm{M}$ é mercadoria, $\mathrm{D}$ é dinheiro e $\mathrm{M}$ é mercadoria), reafirmando, assim, a continuidade das relações não-capitalistas no campo, influenciando a corrente teórica de interpretação, que defende a permanência do campesinato. Isso significa que, de forma contraditória e combinada, ao passo que acontece o avanço do assalariamento, concomitantemente ocorre a ampliação do campesinato (OLIVEIRA, 2007).

Além de Rosa Luxemburgo, outros autores influenciaram essa forma de interpretação do campo brasileiro, conforme esclareceu Oliveira (1999; 2007). É neste processo contraditório da própria teoria marxista, que se insere a análise da questão agrária no âmbito da Geografia Agrária brasileira. O conjunto de problemas relacionados ao espaço agrário perpassa, assim, por diferentes visões de mundo, que alicerçam distintas compreensões teóricas.

Segundo Oliveira (1999), é possível perceber três vertentes marxistas sobre o desenvolvimento do campo, sendo que duas delas apontam para a destruição do campesinato e uma defende a sua permanência: 1. A tese da permanência das relações feudais no campo; 2. A tese da destruição dos camponeses e a modernização dos latifúndios; e, 3. A tese da criação e a recriação do campesinato e do latifúndio. Em relação a essa primeira corrente, o autor esclarece:

O estudo da agricultura brasileira tem sido feito por muitos autores marxistas que expressam diferentes vertentes do pensamento marxista. Alguns autores defendem o ponto de vista de que no Brasil houve feudalismo, ou mesmo relações semifeudais de produção. Por isso eles advogam a seguinte tese: para que o campo se desenvolva seria preciso acabar com essas relações feudais ou semifeudais e ampliar o trabalho assalariado no campo. Para esses autores, a luta dos camponeses contra os latifundiários exprimiria o avanço da sociedade na extinção do feudalismo. Portanto, a luta pela reforma agrária seria um instrumento que faria avançar o capitalismo no campo. Esses autores costumam afirmar inclusive que o capitalismo está penetrando no campo. Entre os principais estudiosos que seguem essa concepção estão Maurice Dobb, Nelson Werneck Sodré, Alberto Passos Guimarães, Inácio Rangel etc. (OLIVEIRA, 1999, p. 70) 
No que se refere à tese da destruição do campesinato e a modernização do latifúndio, apresentada por significativo número de trabalhos da Geografia com base nessa concepção, Oliveira (1999, p. 71) destaca:

\begin{abstract}
Outra vertente entende que o campo brasileiro já está se desenvolvendo do ponto de vista capitalista e que os camponeses inevitavelmente irão desaparecer, pois eles seriam uma espécie de "resíduo" social que o progresso capitalista extinguiria. Ou seja, os camponeses ao tentar produzir para o mercado acabariam indo à falência e perdendo suas terras para os bancos ou mesmo teriam que vender para saldar as dívidas. Com isso, os camponeses tornar-se-iam proletários. Entre os principais pensadores dessa corrente estão Karl Kautsky, Vladimir Lenin, Léo Huberman, Paul Sweezy, Caio Prado Jr., Maria Conceição D’incao e Mello, José Graziano da Silva, Ricardo Abromovay etc.
\end{abstract}

E, por fim, em relação à terceira corrente, que revela a permanência do campesinato e do latifúndio no campo, corrente que demarca o lugar histórico do campesinato, enxergando-o como classe social, no âmbito do desenvolvimento contraditório e combinado do capitalismo. Oliveira (1999, p. 73), que acompanha e participa da construção das ideias dessa corrente e critica as duas primeiras, explicita:

Dessa forma, para mim, que faço parte de uma outra concepção teórica do desenvolvimento do capitalismo no campo, o que ocorre na agricultura brasileira é um processo diferente. $\mathrm{O}$ estudo da agricultura brasileira deve ser feito levandose em conta que o processo de desenvolvimento do modo capitalista de produção no território brasileiro é contraditório e combinado. Isso quer dizer que, ao mesmo tempo que esse desenvolvimento avança reproduzindo relações especificamente capitalistas (implantando o trabalho assalariado pela presença no campo do bóia-fria), ele (o capitalismo) produz também, igual e contraditoriamente, relações camponesas de produção (pela presença do trabalho familiar no campo). Entre os mais importantes pensadores dessa corrente estão Rosa Luxemburgo, Teodor Shanin, Samir Amin e Kostas Vergopoulos, e no Brasil, José de Souza Martins, Margarida Maria Moura, José Vicente Tavares etc. Na geografia agrária, seguindo esta concepção, os trabalhos de Regina Sader, Iraci Palheta, Rosa Ester Rossini, os meus próprios, e as dissertações e teses de grande parte de nossos orientandos.

Oliveira (1999) critica ainda, os autores que acreditam que a sociedade capitalista é composta unicamente por duas classes sociais: a burguesia (os capitalistas) e os proletariados (os trabalhadores assalariados). Contesta as outras duas abordagens, que defendem a tendência ao desaparecimento do camponês e afirma que "é por isso que muitos autores e mesmo partidos políticos não assumem a defesa dos camponeses” (OLIVEIRA, 1999, p. 71). 
Penso que esses autores esqueceram uma frase escrita por Karl Marx em O Capital: "os proprietários de mera força de trabalho, os proprietários de capital e os proprietários de terra, cujas respectivas fontes de rendimento são o salário, o lucro e a renda fundiária, portanto, assalariados, capitalista e proprietários de terra, constituem as três grandes classes na sociedade moderna, que se baseia no modo de produção capitalista". Portanto, a compreensão do papel e do lugar dos camponeses na sociedade capitalista e no Brasil, em particular, é fundamental. Ou entende-se a questão no interior do processo de desenvolvimento do capitalismo no campo, ou então continuar-seá a ver muitos autores afirmarem que os camponeses estão desaparecendo; entretanto, os camponeses continuam lutando para conquistar o acesso à terra no Brasil. (OLIVEIRA, 1999, p. 72) (Grifos nossos)

Martins (1981) afirma, nesse sentido, que estamos diante da sujeição da renda da terra camponesa ao capital e não do fim do campesinato. Do ponto de vista histórico, o processo de sujeição da renda da terra camponesa antecedeu o próprio modo capitalista de produção. No modo feudal, a renda da terra camponesa era apropriada pelo senhor feudal, por meio do regime de servidão, seja renda em trabalho, seja renda em produto. Posteriormente, no momento de transição para o capitalismo, com o monopólio das terras, surgiu a renda em dinheiro (OLIVEIRA, 2007).

Cumpre ressaltar que, o desenvolvimento do capitalismo no campo, após o processo de transição do feudalismo, ocorreu de forma heterogênea no tempo e no espaço. Se em alguns países, como a Inglaterra foi impossibilitada a continuidade da agricultura camponesa nesse período, outros garantiram sua reprodução, a exemplo da França, após a Revolução Francesa. Além disso, vale lembrar as distintas formas comunitárias desenvolvidas em diferentes épocas na América, África e Ásia. Isso significa que o camponês não estaria marcado para desaparecer, expressa na sua recriação do mesmo no próprio berço do capitalismo, isto é, na Europa (OLIVEIRA, 2007).

No caso do Brasil, reafirmando as ideias de Martins (1981, p. 175), o processo de reprodução e recriação camponesa acontecem em razão da sujeição ocorrer sem que se dê, necessariamente, a expropriação, isto é, "o movimento do capital não opera, de modo geral, no sentido da separação entre a propriedade e a exploração dessa propriedade [...], fundamentalmente, o capital tende a se apropriar da renda da terra”. Esclarece o autor:

$\mathrm{Na}$ medida em que o produtor preserva a propriedade da terra e nela trabalha sem o recurso do trabalho assalariado, utilizando unicamente o seu trabalho e o da sua família, ao mesmo tempo que cresce a sua dependência em relação ao capital, o que temos não é a sujeição do trabalho ao capital. O que essa relação nos indica é outra coisa, bem distinta: estamos diante da sujeição da renda da terra ao capital. Esse é o processo que se observa hoje claramente em nosso país, tanto em relação à grande propriedade, quanto em relação à propriedade familiar, de tipo camponês. (MARTINS, 1981, p. 175) (Grifos nossos) 
É partindo dessa compreensão teórico-metodológica, que analisaremos os camponeses como categoria de análise a partir da questão agrária (FREITAS, 2017), no contexto do desenvolvimento contraditório e combinado do capitalismo, constituindo base para a geografia camponesa. Outras questões são fundamentais para esse estudo: quem são esses sujeitos camponeses, quais suas origens e características principais? O que motivou sua denominação de "camponeses" ou "campesinato"? A partir dessa análise, tentar encontrar elementos que aproximam essa geografia camponesa da Educação do Campo, debate apresentado na sequência.

\section{A GEOGRAFIA CAMPONESA E AS APROXIMAÇÕES COM A EDUCAÇÃO DO CAMPO}

Analisar o campesinato, trata-se de uma questão complexa, devendo ser estudado de forma específica, tomando como referência suas particularidades em diferentes escalas espaçotemporais, levando em conta o contexto social ao qual está inserido, do ponto de vista político, econômico e cultural, dentre outros. Essas questões alertam para a limitação do uso de generalizações para o entendimento dessa classe, embora seja possível encontrar características análogas do campesinato ${ }^{4} \mathrm{em}$ diferentes lugares do mundo, a exemplo de sua organicidade política, do trabalho de base familiar, sua cultura e (in)sujeição etc. No caso brasileiro, é possível apreender suas origens, seus conceitos e suas diferentes manifestações, a partir das tensões e das lutas por direitos, principalmente, após a segunda metade do XX, motivando a construção de políticas públicas, dentre as quais, a Educação do Campo, elementos que enriquecem o debate sobre a aproximação desse saber com a geografia camponesa.

Shanin (2005), ao apresentar reflexões sobre o sentido do conceito de campesinato, alerta para o fato de que os camponeses diferem de uma sociedade em relação às demais, ou mesmo, dentro de uma mesma sociedade, referindo-se aos problemas de cunho geral e específicos que conformam essa classe. Caberia ao estudioso encontrar as nuances que esclarecem e as que tornam essa teoria ininteligível, refletindo não apenas a realidade imediata, como mostra seus escritos:

[...] O termo campesinato não implica a total semelhança dos camponeses em todo o mundo, e/ou sua existência fora do contexto de uma sociedade mais ampla não-apenas-camponesa e/ou extra-historicidade. Essas ideias são como espantalhos, coisas que as crianças se encantam derrubar. Os camponeses diferem necessariamente de uma sociedade para outra e, também, dentro de uma mesma sociedade; trata-se do problema de suas características gerais e específicas. Os camponeses necessariamente refletem, relacionam-se e interagem com não

\footnotetext{
${ }^{4}$ Campesinato é entendido como a classe social e os(as) camponeses(as) como integrantes, isto é, os sujeitos sociais e políticos que compõem essa classe.
} 
camponeses; trata-se da questão da autonomia parcial de seu ser social. O campesinato é um processo e necessariamente parte de uma história social mais ampla; trata-se da questão da extensão da especificidade dos padrões de seu desenvolvimento, das épocas significativas e das rupturas estratégicas que dizem respeito aos camponeses. O conceito de camponês é seletivo (...). A simples questão: "os camponeses existem?" Seria obviamente tola se colocada e retificada em seu conteúdo; não discutimos aqui a realidade imediata, mas uma generalização, ligada a um modelo conceitual - uma simplificação e uma formalização significativamente seletivas, com o propósito de uma melhor compreensão. Deveríamos, portanto, colocar a questão de outra maneira, perguntando que esclarecimentos pode-se ter pela utilização do conceito e quais são os obscurecimentos em tal teorização. (SANHIN, 2005, p. 18)

Nessa direção, outro aspecto abordado pelo autor, refere-se a incontestável heterogeneidade dos camponeses, sendo possível sua apreensão de forma mais específica, apenas do ponto de vista analítico, dentro de um contexto também específico, semelhante ao tratamento que resguarda os fenômenos sociais diversos (SHANIN, 2005). De modo geral, a relevância da análise do campesinato reside na forma como o mesmo tem contribuído para o conhecimento das sociedades, embora, muitas vezes, usado de forma equivocada, como mistificação.

A heterogeneidade dos camponeses é indubitável. Os camponeses não podem ser, de fato, compreendidos ou mesmo adequadamente descritos sem sua estrutura societária mais geral; e o mesmo é válido para o contexto histórico (na realidade, apenas analiticamente é possível dividir "o diacrônico" e "o sincrônico" nos fenômenos sociais). Enfim, o termo "camponês" pode ser usado, e tem sido usado, como mistificação. Entretanto, dizer tudo isso é apenas limpar o terreno para a discussão das questões centrais que estão em jogo aqui. O que está em pauta é a maneira como esse conceito opera no processo de conhecimento das sociedades. A "definição de camponês" só pode ser entendida dentro desse contexto. (SHANIN, 2005, p. 02)

Considerando as características mais gerais, Shanin (1976, p. 08) apresenta o campesinato como uma entidade social com quatro faces essenciais e interrelacionadas: a) a exploração agrícola familiar como uma unidade básica multifuncional de organização social; b) o cultivo da terra e a criação como principais meios de vida; c) uma cultura tradicional específica, intimamente ligada à forma de vida de pequenas comunidades rurais; e, d) a subordinação em direção de poderosos agentes externos. Em obra publicada posteriormente, o autor reafirma esses elementos do campesinato, além de ressaltar os parâmetros necessários de sua investigação, a partir do estabelecimento rural familiar e suas reações e interações ligadas ao contexto social:

A especificidade do camponês reflete a interdependência entre os elementos básicos [...] e não pode ser pura e simplesmente reduzida a qualquer um deles. Ao mesmo tempo o cerne de suas características determinantes parece repousar na natureza e na dinâmica do estabelecimento rural familiar, enquanto unidade básica de produção e meio de vida social. Consequentemente, a própria existência 
do camponês, como uma entidade social específica, depende da presença de estabelecimentos rurais familiares como a unidade básica da economia e da sociedade. O camponês deve ser compreendido, portanto, através da investigação das características do estabelecimento rural familiar camponês, tanto internas quanto externas, isto é, suas específicas reações e interações com o contexto social mais amplo [...]. (SHANIN, 1983, p. 51-52)

O campesinato mostra-se, assim, como uma classe social com características próprias em contextos diversos, resistindo e subordinando-se ao capital como condição que lhe permite a reprodução social, diante da quase inexistente ajuda do Estado (SHANIN, 1976). Proletariza-se em determinados momentos, parcial ou integralmente, de forma temporária em algumas situações, porém, mantendo seu modo de vida e de reprodução material. Essas diversas faces do campesinato materializam sua existência e permanência no campo, mesmo diante do processo de modernização, considerando que "en la mayoría de las experiencias conocidas, los pobres soportan la carga más pesada de la modernización, tanto bajo los auspícios socialistas como capitalistas [...] (SHANIN, 1976, p. 77).

No caso brasileiro, a discussão sobre o conceito de camponês tem apresentado leituras divergentes em diferentes temporalidades e espacialidades, acompanhando o contexto político, econômico e cultural ao qual esteve inserido. O campesinato assumiu identidade nacional após os anos de 1950, sofrendo mudanças nas ciências sociais em décadas seguintes, frente à implantação de políticas públicas modernizantes e à desarticulação de movimentos sociais à época, sendo incorporado outros conceitos como "pequeno produtor" e "agricultor familiar", em detrimento do conceito camponês e de sua relação com a questão agrária (BOMBARDI, 2003; MARQUES, 2008). Esse conceito, no entanto, ressurgiu após 1990, como forma de crítica ao contexto de expansão da industrialização da agricultura capitalista, devido aos impactos à natureza e ao seu caráter de espoliação (MARQUES, 2008).

Os termos "camponês" e "campesinato", nesse sentido, são palavras recentes no Brasil, "chegadas pelo caminho da importação política" (MARTINS, 1981, p. 21) e introduzidos pela esquerda, em meados do século XX, que tentavam dar conta das lutas dos trabalhadores do campo em diversos pontos do país contra as desigualdades sociais etc. Anterior a esse período, aos camponeses era atribuído diversas denominações como caipira, caiçara, tabaréu, caboclo etc., segundo descreveu Martins (1981, p. 21-22):

[...] Antes disso, um trabalhador parecido, que na Europa e em outras países da América Latina é classificado como camponês, tinha aqui denominações próprias, específicas até em cada região. Famoso tornou-se o caipira, palavra provavelmente de origem indígena, usada para designar o camponês das regiões de São Paulo, Minas Gerais, de Goiás, do Paraná, do Mato Grosso do Sul. No litoral paulista, esse mesmo trabalhador é denominado de caiçara. No Nordeste 
do país, chamam-no de tabaréu. Noutras partes é conhecido como caboclo, palavra muito difundida que quer dizer diferentes coisas em diferentes épocas e em diferentes lugares: em São Paulo do século XVII era designação depreciativa pela qual se nomeavam os mestiços de índios e brancos; o Norte e no Centro-Oeste do país é palavra empregada para distinguir o pagão do cristo, sendo nome que se dá ao índio, mesmo em contato com o branco; em várias regiões é palavra que designa o homem do campo, o trabalhador.

As denominações dos camponeses foram utilizadas, historicamente, com duplicidade e de forma pejorativa, em geral, referindo-se "aos que vem de longe, no campo, fora das povoações e das cidades, e que, por isso, são também 'rústicos', 'atrasados', ou então, 'ingênuos', inacessíveis, além do sentido de 'tolo', de 'tonto"' (MARTINS, 1981, p. 22). De acordo com esse autor, imputaram também aos camponeses o termo "preguiçoso", que não gosta de trabalho, análogo ao ocorrido com as populações originárias (indígenas). Esses termos depreciativos, aos poucos, foram se tornando inúteis, enquanto a palavra camponês foi ganhando força e tendo um caráter político mais expressivo, assim como campesinato, sua classe social, portadora de direitos. Esses elementos inclusive revelaram "um crescimento das lutas camponesas e a entrada da situação do campesinato no debate político nacional” (MARTINS, 1981, p. 22).

O referido autor mostra, ainda, que semelhante aos camponeses, seu par dialético, isto é, os latifundiários, também tinham denominações diferenciadas, conforme a região e atividade. Eram chamados de estancieiros no Sul; de fazendeiros em São Paulo, Rio de Janeiro e Minas Gerais; senhores de engenho no Nordeste; e de seringalistas no Norte. Sua denominação foi alterada no contexto da questão da luta de classes, isto é, passando a serem chamados de latifundiários, vinculando-se, sobretudo, à concentração da propriedade privada da terra e sua improdutividade. De acordo com Martins (1981, p. 22-23):

Essas novas palavras - camponês e latifundiário - são palavras políticas que procuram expressar a unidade das respectivas situações de classe e, sobretudo, que procuram dar unidade às lutas dos camponeses. Não são, portanto, meras palavras. Estão enraizadas numa concepção da História, das lutas políticas e dos confrontos entre as classes sociais. Nesse plano, a palavra não designa apenas o seu novo nome, mas também o seu lugar social, não apenas no espaço geográfico, no campo em contraposição à povoação ou à cidade, mas na estrutura da sociedade; por isso não é apenas um novo nome, mas pretende ser também a designação de um destino histórico.

Ambas as palavras, representam essa luta política no contexto da luta de classes, o campesinato em oposição aos latifundiários. Este último, nos dias atuais, denominado ou vinculado ao agronegócio, com práticas semelhantes aos antigos latifundiários, como a concentração da propriedade da terra, trabalho precarizado, inclusive análogo à escravidão em algumas situações, além da sujeição da renda da terra camponesa, embora apresentando especificidades diferenciadas. 
Após as últimas décadas do século XX e o início do século XXI, o Estado brasileiro tem demonstrado, de forma sucessiva, a defesa e apoio ao agronegócio como agricultura predominante, direcionando-a, principalmente, à produção de commodities, refletindo negativamente nas políticas direcionadas ao campesinato, voltadas à produção de alimentos para consumo interno. Esse processo tem uma relação com a continuidade do modelo tripé adotado pela economia política brasileira desde meados do século XX, efetivada pela aliança entre o Estado, capital privado nacional e capital privado internacional (OLIVEIRA, 1981), notadamente ampliada com processo de mundialização do capital (CHESNAIS, 1996), condição a qual o país é incorporado de forma periférica ou semiperiférica, dando continuidade a subordinação histórica vivenciada nesse espaço.

Dessa forma, apesar de a origem do conceito de camponês no Brasil ter uma relação com a realidade europeia, a sua formação remete-se à relação periférica no contexto da expansão do capitalismo, processo que tem acarretado em condições precárias de acesso à terra, em geral, por meio da posse e à margem do latifúndio (MARQUES, 2000; 2008). Esse contexto teria inaugurado o conflito entre a territorialidade camponesa e a territorialidade capitalista, daí Martins (1981) ter afirmado que o camponês assumiu uma identidade política no âmbito nacional após meados do século XX, embora resguardando características próprias nos diferentes espaços brasileiros.

A formação do campesinato brasileiro está relacionada com uma existência dependente como agregado no interior das grandes fazendas e como posseiro ou sitiante, ocupando pequenas áreas em terras marginais, tanto do ponto de vista econômico como espacial. Nesta fase, a base da economia empregava o trabalho escravo, cabendo ao campesinato a produção de gêneros alimentícios de consumo interno. Somente com a crise do trabalho escravo e a necessidade de se assegurar uma oferta de mão-de-obra livre, é que foi promulgada a Lei de Terras em 1850, proibindo a aquisição de terras devolutas por outro meio que não a compra. São, assim, redefinidas as condições de existência do campesinato, que, a partir daí fica impedido formalmente de se estabelecer na terra por meio da posse. Inaugura-se o conflito entre a territorialidade camponesa e a territorialidade capitalista. (MARQUES, 2000, p. 11-12)

No Nordeste, segundo Oliveira; Stedile (2005, p. 10), o campesinato formou-se tendo como origem os "trabalhadores agrícolas de origem mestiça, que não podiam ser escravizados, mas que não tinham direito à terra. Eles iam se embrenhando pelo sertão adentro, em busca de terras públicas nas quais pudessem cultivar e sobreviver com suas famílias[...]”. Ressaltando que tal "miscigenação" incluiu os povos originários (indígenas) de forma forçada, por meio de violência cometida pelos colonizadores que adentraram no sertão (PINHEIRO, 2008).

Apesar de toda violência e negação de direitos, ao longo dos anos, o campesinato continua existindo, como mostra a concretude de sua insujeição revelada pelas guerras, revoltas e lutas históricas por terra e território e, mais recentemente, por reforma agrária. Além disso, como 
mostrou Martins (1981), os camponeses sempre estiveram um passo à frente dos partidos políticos no país, pelo caráter utópico de suas lutas. A princípio, a insujeição se deu contra a dominação dos fazendeiros e "coronéis", em seguida, contra a "expropriação" e exploração geridos pelos latifundiários e grileiros (MARTINS, 1981), hodiernamente denominados de agronegócio, uma cara nova com as velhas estratégias de concentração da propriedade privada da terra, fortemente incentivado pela política econômica do Estado.

Esses mecanismos do latifúndio-agronegócio, com o intuito de subjugar o trabalho, tem encontrado no Estado a garantia histórica de políticas voltadas aos seus interesses, frequentemente gerando diversos conflitos, expulsões violentas de camponeses, como tem expressado os relatórios produzidos pela Comissão Pastoral da Terra (CPT), ao longo dos anos. O campesinato, por sua vez, recria-se em outros espaços, na maioria das vezes, como posseiros, em condições extremamente precárias de reprodução social e (i)material.

A esse respeito, pode-se mencionar o caso das Ligas Camponesas, irrompendo em vários pontos do país, após meados do século XX. De acordo com Fernandes; Porto-Gonçalves (2000, p. 67), o objetivo inicial das Ligas Camponesas fora o de "defender o interesse dos mortos e não os dos vivos. Os interesses dos mortos de fome e de miséria". Suas reivindicações, de início, se restringiam ao direito de os camponeses terem "sete palmos de terra", onde pudessem ser sepultados com caixão de sua propriedade, posteriormente, ganhou caráter político mais expressivo, constituindo-se a luta por terra para reprodução material da vida e pela reforma agrária.

Após esse período, as políticas de "modernização" do Estado atingiram os camponeses em todo o país, ligados à terra por várias gerações, tornando-os repentinamente ameaçados ou expulsos, submetidos a todo tipo de violência (MARTINS, 1981, p. 11). A multiplicação dos conflitos pela terra revelou outros protagonistas, embora o camponês posseiro tivesse se tornado o principal, demonstrando, assim, uma diferenciação da própria base social em luta por reforma agrária, organizada principalmente, pelo Movimentos dos Trabalhadores Sem Terra (MST).

Apesar da expressividade das lutas e da insujeição dos camponeses, essa classe foi considerada, muitas vezes, como um “erro histórico" por aqueles que não reconhecem seu papel e permanência no campo. Isso se deve, em alguns casos, à visão social de mundo de alguns estudiosos, que acreditam ser necessário ampliar a classe operária no campo e na cidade. Dessa forma, com a completa expropriação do trabalhador, tornando-se em assalariado, este se conformaria antagônico com o capital, surgindo assim, a possibilidade de transformação social. Esse processo seria impedido pelo camponês, que se negaria à expropriação (MARTINS, 1981, p. 13).

Essas questões revelam a falta de compreensão sobre os sujeitos camponeses. De acordo com Martins (1980), ao se sentirem ameaçados à expulsão de sua terra, ao desenraizamento, vão 
lutar, constituindo-se classe social, na medida em que o capital tenta arrancá-los do seu "chão". Para o autor, os camponeses cometem uma traição às leis do capital, enquanto característica do seu papel histórico de insubmissão, ainda que esse processo não ocorra de forma generalizada, ou seja, “o capital se expande no campo, expulsa, mas não proletariza o trabalhador. É que uma parte dos expropriados ocupa novos territórios, reconquista autonomia do trabalho, pratica uma traição às leis do capital" (MARTINS, 1980, p. 17).

Martins (1981) destaca ainda, a necessidade de analisar essas questões do ponto de vista político, no âmbito da luta das classes sociais, daí a necessidade de uma resposta também política e não meramente econômica ou teórica. Não se trataria apenas de um convencimento ao camponês de sua expropriação e transformação em proletariado, pois seria a forma profeticamente pensada por Marx, a partir de alguns de seus seguidores, ao decidiram que a história (concreta) tinha de confirmar suas perspectivas de análises. Martins (1981, p. 13) esclarece:

Seria, entretanto, pura imbecilidade tentar convencer o camponês que está sendo despejado, cuja casa está sendo queimada pelo jagunço e pela polícia, que deve aceitar tal fato como uma contingência histórica, como ocorrência que é ruim pra ele, mas é boa para a humanidade (ou ao menos para os ideólogos e justificadores de tais violências e injustiças), pois é o que vai permitir o desenvolvimento do capital, daquele mesmo que o antagoniza patrocinando tais violências[...] Esse é um problema que precisa de resposta e resposta política. A questão é saber se a ação política e o sentido político das lutas sociais encontram sua importância histórica nas coisas como são ou nas coisas como deveriam ser, nos fatos concretos vividos pelo campesinato em suas relações visíveis e claras, e em suas ocultas, ou nas fantasias dos intelectuais pretensamente descomprometidos.

Reafirmando essa concretude e (in)sujeição camponesa no espaço brasileiro, cumpre destacar a análise de Tavares dos Santos (1978), sobre colonos descendentes de italianos, do Rio Grande do Sul, mostrando os impasses de sua condição social e os empecilhos históricos à sua reprodução social. Uma contribuição relevante de sua obra, refere-se à forma como delineia os elementos que constituem os camponeses, caracterizando-os a partir dos seguintes condicionantes: a força de trabalho familiar; as práticas de ajuda mútua; o trabalho acessório do camponês; a força de trabalho assalariada (temporária); a socialização do camponês; a propriedade da terra; a propriedade dos meios de produção; a jornada de trabalho; e a reprodução simples da produção camponesa. Essa abordagem tem sido fundamental, assim como as demais anteriores, para os estudos da geografia camponesa.

Assim, a análise geográfica dos(as) camponeses(as) - no contexto amplo da sociedade, considerando suas temporalidades e espacialidades, analisadas na construção do território e materializada pelas lutas históricas por territorialização e territorialidade - nos mostra algumas pistas importantes acerca de sua aproximação com a Educação do Campo, consubstanciadas 
através das relações teórico-metodológicas e, do ponto de vista empírico, pelas demandas concretas dessas lutas camponesas, situadas no contexto do conhecimento produzido por esses campos de saberes.

A abordagem sobre a luta pelo direito à educação, além do aspecto do conhecimento, tem sido um parâmetro essencial para assegurar a permanência dos sujeitos nas comunidades camponesas, processo que fortalece a recriação do campesinato. É nesse contexto que a Educação do Campo efetivou-se, resultando das lutas dos movimentos sociais, populares, sindicais e religiosos (vinculados à teoria da libertação), em conjunto com estudiosos engajados com a defesa dos direitos dos/as camponeses/as de manterem sua condição de reprodução social e modo de vida atrelada à cultura camponesa.

A luta por Educação do Campo teve como objetivo uma educação contextualizada para o campo, em contraposição ao formado de Educação Rural, construída a partir dos estudos urbanos transferidos ao campo, desconsiderando o contexto histórico, socioeconômico, cultural, organicidade política etc. dos camponeses e povos do campo. Caldart (2010, p. 106) apresenta esse e outros elementos que deram nascimento à Educação do Campo:

A Educação do Campo nasceu como crítica à realidade da educação brasileira, particularmente à situação educacional do povo brasileiro que trabalha e vive no/do campo. Essa crítica nunca foi à educação em si mesma porque seu objeto é a realidade dos trabalhadores do campo, o que necessariamente a remete ao trabalho e ao embate entre projetos de campo que têm consequências sobre a realidade educacional e o projeto de país. Ou seja, precisamos considerar na análise que há uma perspectiva de totalidade na constituição originária da Educação do Campo. E tratou-se primeiro de uma crítica prática: lutas sociais pelo direito à educação, configuradas a partir da realidade da luta pela terra, pelo trabalho, pela igualdade social, por condições de uma vida digna de seres humanos no lugar em que ela aconteça. É fundamental considerar, para a compreensão da constituição histórica da Educação do Campo, seu vínculo de origem com as lutas por educação nas áreas de Reforma Agrária e como, especialmente nesse vínculo, a Educação do Campo não nasceu como uma crítica apenas de denúncia, mas como contraponto de práticas, construção de alternativas, de políticas, ou seja, como crítica projetiva de transformações.

A formulação da política de Educação do Campo surge nesse movimento, tendo como marco a I Conferência Nacional por uma Educação Básica do Campo, realizada em Luziânia, Goiás, no ano de 1998, passando a ser denominada Educação do Campo a partir das discussões do Seminário Nacional realizado em Brasília, de 26 a 29 de novembro 2002, bem como, nos debates da II Conferência Nacional, em julho de 2004 (CALDART et al., 2012). Com a criação do Programa Nacional de Educação na Reforma Agrária (PRONERA), instituído em 1998, a Educação do Campo é reafirmada no contexto de políticas públicas específicas para os camponeses. 
A Educação do Campo no Brasil, como destacam Molina (2015) e Arroyo; Caldart; Molina (2011), refere-se a um saber compreendido como prática de liberdade, condicionando processos formativos, a partir de referencial teórico-metodológico, em conformidade com a alternância pedagógica, articulando dois tempo-espaço formativos: o Tempo-Universidade (TU), voltado à abordagem teórica, com debates em sala de aula; e o Tempo-Comunidade (TC), pensado a partir da relação direta com as comunidades e os movimentos sociais.

Vale ressaltar a reflexão de Batista; Molina (2015), ao afirmarem que a Educação do Campo assume a disputa como política pública, não apenas objetivando o acesso à educação, mas sobretudo, por considerar o direito dos sujeitos do campo à educação nos seus contextos locais e de acordo com suas necessidades humanas e sociais, considerando sua cultura e seus desafios para reprodução material da vida nos diferentes territórios do campo. Nesse sentido, as autoras afirmam que "a Educação do Campo tem se constituído um projeto de educação emancipadora, a partir da luta pela terra e pelo acesso ao conhecimento pelos camponeses, como parte da luta, para, como tal, continuarem garantindo sua existência” (BATISTA; MOLINA, 2015, p. 18).

Segundo Caldart (2010), esse projeto educativo concebido vincula-se a uma educação regida sobre o princípio do direito dos povos do campo, sendo que a relação entre educação e trabalho é compreendida como um dos elementos centrais. Nessa perspectiva, a autora destaca o direito a terra, às sementes e à água, a soberania alimentar, a agroecologia e a cooperação agrícola como possibilidades de conformarem seus princípios organizadores. Essas discussões alinham-se aos debates e estudos realizados na Geografia Agrária, elementos que aproximam tais saberes e intencionalidades alicerçadas na práxis (FREIRE, 1980).

A Educação do Campo compreende, assim, processos educativos que pretendem formar sujeitos construtores da sua história - intelectuais orgânicos, na concepção gramsciana. Uma educação pautada pelo protagonismo dos movimentos sociais, em conjunto com os demais sujeitos construtores dessa política pública, tais como educadores comprometidos com o pensamento crítico, dentre outros. Nesse contexto, pode-se destacar a contribuição das Licenciaturas em Educação do Campo (LEdoC), respaldadas pela metodologia da alternância, essencial para reafirmação dos direitos dos povos do campo, considerando suas especificidades, contextos e lutas.

Essas perspectivas teórico-práticas da Educação do Campo aproximam-se dos estudos e saberes da Geografia Humana - a partir da Geografia Agrária, mas especificamente dos estudos camponeses -, conforme às abordagens teórico-metodológicas, já apresentadas no decorrer deste texto. Para tanto, alguns elementos teóricos da Geografia, vinculados à pesquisa e à extensão, de maneira mais sistemática, podem servir como parâmetro dessa aproximação, contribuindo para 
uma análise interdisciplinar entre esses ramos de conhecimento, conforme podemos verificar na sequência:

a) o espaço social, compreendido como a "materialização da existência humana", resultante da relação entre a sociedade e a natureza, mediada pelo trabalho e técnicas (na acepção filosófica), conforme as abordagens lefebvrianas e miltonianas. A análise dos espaços sociais das comunidades camponeses pode ser relacionada com o debate sobre a educação e o trabalho;

b) a análise da construção do território, interpretado a partir das relações sociais, como produto concreto da luta de classes travada pela sociedade no processo de produção de sua existência, considerando as relações de poder e multidimensionalidade territorial (OLIVEIRA, 1999; RAFFESTIN, 1993), interrelacionada aos aspectos da luta por Educação do Campo contextualizada;

c) a territorialização camponesa como expressão da permanência na terra e no território, por meio dos estudos das resistências nos acampamentos, assentamentos, comunidades camponesas e territórios indígenas, incluindo as experiências de educação popular e das escolas do campo presentes nesses espaços;

d) a territorialidade camponesa, a partir da interpretação e defesa das identidades camponesas e dos povos originários, a partir da análise dos processos de reafirmação do reconhecimento desses territórios, considerando a relação identitária vinculada à terra e ao modo de vida, compreendida na dimensão cultural, antropológica e sua relação com os processos educativos;

e) o estudo da Agroecologia, entendida com base em seus princípios econômicos, políticos, culturais, ambientais, éticos etc. Elementos analisados na produção do espaço rural, compreendido como produto da relação e interação entre a sociedade e a natureza, em que as experiências agroecológicas podem gerar processos educativos por meio da troca de saberes entre os sujeitos sociais e políticos;

f) a alternância pedagógica como parâmetro que possibilita os estudos agrários durante o "Tempo Comunidade", através das análises de realidades do campo, expressando diferentes problemáticas envolvendo a questão agrária nesses espaços, estratégias de organicidade coletiva, dentre outros aspectos;

g) a cartografia social como estratégia educativa e de participação política, tornando-se instrumento de luta em defesa de direitos, espacialização das problemáticas, organicidade política e empoderamento dos/das camponeses/as como sujeitos portadores de direitos;

h) o estudo da monopolização do território pelo capital, a partir da análise das formas de subordinação do campesinato ao capital e as estratégias educativas de construção de alternativas de 
produção e comercialização, como feiras camponesas de base agroecológicas, fomentando a autonomia camponesa;

i) a análise do uso e implicações dos agrotóxicos à saúde humana e ambiental (RIGOTTO, 2011), vinculada ao debate da questão agrária, com base em metodologias participativas, contando com a elaboração de mapas sociais (croquis), a realização de oficinas e cursos (incluindo a interpretação de imagens e mapas) e a exibição e debate de vídeos e documentários sobre o tema;

j) a compreensão sobre a territorialização do capital no campo, a partir da análise da expansão do agronegócio e da (in)sujeição do território camponês ao capital (FREITAS, 2017), verificando os impactos socioambientais para a reprodução (i)material da vida camponesa, além das mudanças no processos educacionais, tais como o fechamento das escolas do campo, dentre outros;

1) a análise da geografia camponesa, a partir da caracterização e das especificidades que constituem as espacialidades da agricultura camponesa, vinculada ao debate da questão agrária e da economia política do campesinato (SHANIN, 1976; 2008; 2017; OLIVEIRA, 1981; 1991), relacionadas ao contexto societal, compreendendo o papel dos sujeitos sociais e políticos, do Estado e do capital privado nesse processo.

\section{PARA NÃO CONCLUIR}

Para não concluir, o texto tem relação com o debate ainda inicial aqui tratado, cujo aprofundamento dependerá de análises posteriores, o que não significa inviabilizar algumas reflexões a partir das questões apresentadas. A princípio, é possível verificar a dificuldade do trabalho interdisciplinar em relacionar diferentes campos de saberes de forma mais sistemática, embora algumas aproximações mostrem-se apreensíveis. No caso da geografia camponesa e da Educação do Campo, a luta pela permanência na terra e as re-existências dos camponeses e povos do campo são exemplos concretos que fomentam a análise teórica de caráter interdisciplinar por esses ramos de estudos. Para tal, o percurso de análise escolhido trouxe uma abordagem filosófica e teórica, com intuito de dar sustentação a essa relação, a partir do olhar da Geografia, pautado no pensamento crítico.

Em relação aos aportes filosóficos, é possível examinar que os mesmos motivaram as escolhas teórico-metodológicas sobre a recriação do campesinato ou sua extinção. A reflexão evidencia que defender ou negar a existência dos camponeses vinculam-se às visões sociais de mundo dos estudiosos. O problema e a forma de abordá-lo, portanto, tem a ver com a questão de método e com os valores do investigador, assim, de caráter ontológico, seja considerando a acepção utópica revolucionária como forma subversiva à ordem social desigual, seja pela manutenção dessa 
ordem fortalecida nas premissas naturalizantes dos fatos e dos fenômenos sociais pelo discurso da neutralidade científica, dentre outros.

Sobre o campesinato, percebe-se que não se trata de tarefa fácil compreender essa classe, inclusive, como categoria de análise, tornando-se essencial a consolidação de uma geografia camponesa no âmbito da Geografia Agrária. Autores como Ariovaldo Umbelino de Oliveira, já anunciara a relevância desses estudos na geografia brasileira, assim como parte significativa de seus orientandos, a exemplo de Paulino (2006), Bombardi (2003) e Marques (2008). Acerca do conceito de camponês ou campesinato, como mostrou Shanin (2005), há razões para discuti-lo, assim como há razões para deixar essa palavra indefinida, sendo válido fazer um teste do conceito ou voltar às suas raízes, tentativa deste trabalho. Entender o campesinato, seu modo de vida e de reprodução social requer, portanto, um olhar atento as manifestações, especificidades análogas e diferenciadas dessa classe que permanecem no campo brasileiro.

Por fim, a análise interdisciplinar dos estudos geográficos sobre os(as) camponeses(as) no contexto da questão agrária mostra-se uma importante ferramenta de aproximação com a Educação do Campo. Espera-se que esse ensaio possa suscitar debates e novas inquietações e que os sujeitos do campo se fortaleçam com esse encontro entre a Geografia e a Educação do Campo. É sabido que, muitas questões ainda precisam ser aprofundadas sobre esse tema, daí o caráter inconcluso deste artigo, aberto à crítica e à provocação.

\section{REFERÊNCIAS}

ABRAMOVAY, Ricardo. Paradigmas do capitalismo agrário em questão. 3. ed. São Paulo: Edusp, 2007.

ALVES, Vicente Eudes Lemos; LIMA, Débora Assumpção. Questões rurais e campesinato: uma entrevista com Teodor Shanin. Revista NERA, São Paulo, v. 21, n. 44, p. 236-244, set./dez., 2018.

ARROYO, Miguel Gonzales; CALDART, Roseli Salete; MOLINA, Mônica Castagna (Orgs.). Por uma Educação do Campo. Petrópolis: Vozes, 2011.

BATISTA, Juliana Andréa Oliveira; MOLINA, Mônica Castagna. A licenciatura em Educação do Campo. In: FONTURA, Jara Lourenço da Fontoura et al. (Orgs.). Vozes do campo: ressignificando saberes e fazeres. São Leopoldo: Oikos, 2015. p. 13-40.

BOMBARDI, Larissa Mies. O papel da geografia agrária no debate teórico sobre os conceitos de campesinato e agricultura familiar. Geousp, São Paulo, n 14, p. 107-117, 2003.

CALDART, Roseli Salete. Educação do Campo: notas para uma análise de um percurso. In: MOLINA, Mônica Castagna (Org.). Educação do campo e pesquisa II: questões para reflexão. Brasilia: MDA/MEC, 2010. p. 103-126. 
CALDART, Roseli Salete et al. (Orgs.) Dicionário da Educação do Campo. Rio de Janeiro: Escola Politécnica de Saúde Joaquim Venâncio; São Paulo: Expressão Popular, 2012.

CHESNAIS, François. A mundialização do capital. São Paulo: Xamã, 1996.

FERNANDES, Bernardo Mançano; PORTO-GONÇALVES, Carlos Walter. Josué de Castro: vida e obra. São Paulo: Expressão Popular, 2000.

FREIRE, Paulo. Conscientização: teoria e prática da libertação: uma introdução ao pensamento de Paulo Freire. Trad. Kátia de Mello e Silva. 3. ed. São Paulo: Moraes, 1980.

FREITAS, Bernadete Maria Coêlho. Campesinato, uso de agrotóxicos e sujeição da renda da terra ao capital no contexto da expansão da Política Nacional de Irrigação no Ceará. 2017. 325 f. Tese (Doutorado em Geografia Humana) - Universidade de São Paulo, São Paulo, 2017.

KOSIK, Karel. A dialética do concreto. Trad. Célia Neves e Alderico Toríbio. 3. ed. Rio de Janeiro: Paz e Terra, 1976.

LEFEBVRE, Henri. E1 materialismo dialectico. Buenos Aires: Editorial La Pleyade, 1975.

LENIN, Vladimir. O desenvolvimento do capitalismo na Rússia: o processo de formação do mercado interno para a grande indústria. Trad. José Paulo Netto. São Paulo: Abril Cultural, 1982.

LOWY, Michael. As aventuras de Karl Marx contra o barão de Münchhausen: marxismo e positivismo na sociologia do conhecimento. 9. ed. São Paulo: Cortez, 2007.

LUXEMBURGO, Rosa. A acumulação do capital: contribuição ao estudo econômico do imperialismo. V. I e II. Trad. Marijane e Vieira Lisboa e Otto Erich Walter. 3. ed. São Paulo: Nova Cultura, 1988.

MARQUES, Marta Inez de Medeiros. De sem-terra a "posseiro": a luta pela terra e a construção do território camponês no espaço da Reforma Agrária - o caso dos assentados nas fazendas Retiro e Velho-GO. 2000. 237 f. Tese (Doutorado em Geografia) - Programa de Pósgraduação em Geografia. Universidade de São Paulo, São Paulo, 2000.

MARQUES, Marta Inez de Medeiros. A atualidade do uso do conceito de camponês. Revista Nera, Presidente Prudente, n. 12, p. 57-67, 2008.

MARTINS, José de Souza. O cativeiro da terra. São Paulo: Hucitec, 1979.

MARTINS, José de Souza. Expropriação e violência: a questão política no campo. Petrópolis: Hucitec, 1980.

MARTINS, José de Souza. Os camponeses e a política no Brasil: as lutas sociais no campo e seu lugar no processo político. Petrópolis: Vozes, 1981.

MARX, Karl. O Capital. Contribuição à crítica da economia política. Livro 1 V. I. 36.ed. Trad. Reginaldo Sant'Anna. Rio de Janeiro: Civilização Brasileira, 2012. 
MOLINA, Mônica Castagna. A Educação do Campo e o enfrentamento das tendências das atuais políticas públicas. Educação em Perspectiva, Viçosa, v. 6, n 2, p. 378-400, 2015.

MOLINA, Mônica Castagna; HAGE, Salomão Mufarrej. Riscos e potencialidades na expansão dos cursos de Licenciatura em Educação do Campo. Revista Brasileira de Política e Administração da Educação (RBPAE), Goiânia, v. 32, n. 3, p. 805-828, set./dez., 2016.

OLIVEIRA, Ariovaldo Umbelino de. Agricultura e indústria no Brasil. Boletim Paulista de Geografia, São Paulo, n. 58, p. 05-64, 1981.

OLIVEIRA, Ariovaldo Umbelino de. A agricultura camponesa no Brasil. São Paulo: Contexto, 1991.

OLIVEIRA, Ariovaldo Umbelino de. Geografia agrária e as transformações territoriais recentes no campo brasileiro. In: CARLOS, Ana Fani Alessandri (Org.) Novos caminhos da Geografia. São Paulo: Contexto, 1999, p. 63-110.

OLIVEIRA, Ariovaldo Umbelino de. Modo capitalista de produção, agricultura e reforma agrária. São Paulo: FFLCH/Labur Edições, 2007.

OLIVEIRA, Ariovaldo Umbelino de. A mundialização da agricultura brasileira. São Paulo: Iandé Editorial, 2016.

OLIVEIRA, Ariovaldo Umbelino de; STEDILE, João Pedro. A natureza do agronegócio. São Paulo: Via Campesina, 2005.

OLIVEIRA, Francisco de. Elegia para uma re(li)gião: SUDENE, Nordeste. Planejamento e conflito de classes. 3. ed. Rio de Janeiro: Paz e Terra, 1981.

PAULINO, Eliane Tomiasi. Por uma geografia dos camponeses. São Paulo: Editora UNESP, 2006.

PINHEIRO, Francisco José. Notas sobre a formação social do Ceará (1680-1820). Fortaleza: Fundação Ana Lima, 2008.

RAFFESTIN, Claude. Por uma geografia do poder. São Paulo: Ática, 1993.

RIGOTTO, Raquel Maria (Org.). Agrotóxicos, trabalho e saúde: vulnerabilidade e resistência no contexto da modernização agrícola no Baixo Jaguaribe. UFC/Expressão Popular, 2011.

SHANIN, Teodor. Naturaleza y lógica de la economia campesina. Barcelona: Editorial Anagrama, 1976.

SHANIN, Teodor. La classe incómoda: sociologia politica del campesinato em uma sociedade em desarrollo (Russia 1910-1925). Versão española de Fernando Andrada Tapia. Madrid: Alianza Editorial, 1983.

SHANIN, Teodor. A definição de camponês: conceituações e desconceituações - o velho e o novo em uma discussão marxista. Revista Nera, Presidente Prudente, n. 7, p. 1-21, jul./dez., 2005. 
SHANIN, Teodor. Lições camponesas. In: PAULINO, Eliane Tomiasi; FABRINI, João Edmilson (Orgs). Campesinato e territórios em disputa. São Paulo: Expressão Popular, 2008, p. 23-47.

SHANIN, Teodor (Org.). Marx tardio e a via russa: Marx e as periferias do capitalismo. São Paulo: Expressão Popular, 2017.

TAVARES DOS SANTOS, José Vicente. Colonos do vinho: estudo sobre a subordinação do trabalho camponês ao capital. São Paulo: Hucitec, 1978.

WOLF, Eric Roberto. Guerras camponesas do século XX. Rio de Janeiro: Editora Global, 1984. 